\title{
Mortality incidence and its determinants after fragility hip fractures: a prospective cohort study from an Egyptian level one trauma center
}

\author{
Mohammad K Abdelnasser ${ }^{1}$, Ahmed A Khalifa ${ }^{2}$, Khaled G Amir ${ }^{1}$, Mohammad A Hassan ${ }^{1}$, \\ Amr A Eisa ${ }^{1}$, Wael Y El-Adly ${ }^{1}$, Ahmed K Ibrahim ${ }^{3}$, Osama A Farouk ${ }^{1}$, Hossam A Abubeih ${ }^{1}$
}

1. Orthopedic Department, Assiut University Hospital, Assiut, Egypt.

2. Orthopedic Department, Qena faculty of medicine and its University Hospital, South valley university, Qena, Egypt.

3. Public Health and Community Medicine Department, faculty of medicine, Assiut University, Assiut, Egypt.

\section{Emails:}

Mohammad K Abdelnasser: Abdelnasser.m.k@aun.edu.eg; Khaled G Amir: Khaledalamir@yahoo.com; Mohammad A Hassan: moalaa1989@gmail.com; Amr A Eisa: dr.amratefortho1@gmail.com; Wael Y El-Adly: eladlyw@gmail.com; Ahmed K Ibrahim: ahmed.ibrahim@aun.edu.eg; Osama A Farouk: osama_farouk@yahoo. com; Hossam A Abubeih:hossamabubeih@hotmail.com

\begin{abstract}
Background: Fragility hip fracture is a common condition with serious consequences. Most outcomes data come from Western and Asian populations. There are few data from African and Middle Eastern countries.

Objective: The primary objective was to describe mortality rates after fragility hip fracture in a Level-1 trauma centre in Egypt. The secondary objective was to study the causes of re-admissions, complications, and mortality.

Methods: A prospective cohort study of 301 patients, aged $>65$ years, with fragility hip fractures. Data collected included sociodemographic, co-morbidities, timing of admission, and intraoperative,ostoperative, and post-discharge data as mortality, complications, hospital stay, reoperation, and re-admission. Cox regression analysis was conducted to investigate factors associated with 1-year mortality.

Results: In-hospital mortality was $8.3 \%$ (25 patients) which increased to $52.8 \%$ (159 patients) after one year; 58.5\% of the deaths occurred in the first 3-months. One-year mortality was independently associated with increasing age, ASA 3-4, cardiac or hepatic co-morbidities, trochanteric fractures, total hospital stay, and postoperative ifection and metal failure.

Conclusion: Our in-hospital mortality rate resembles developed countries reports, reflecting good initial geriatric healthcare. However, our 3- and 12-months mortality rates are unexpectedly high. The implementation of orthogeriatric care after discharge is mandatory to decrease mortality rates.
\end{abstract}

Keywords: Fragility hip fractures; trochanteric fractures; mortality rate.

DOI: https://dx.doi.org/10.4314/ahs.v21i2.41

Cite as: Abdelnasser MK, Khalifa AA, Amir KG, Hassan MA, Eisa AA, El-Adly WY, et al. Mortality incidence and its determinants after fragility hip fractures: a prospective cohort study from an Egyptian level one trauma center. Afri Health Sci. 2021;21(2). 806-816. bttps:// dx.doi.org/10.4314/abs.v21i2.41

Corresponding author:
Ahmed A Khalifa,
Assistant Professor and Consultant of
orthopedic and traumatology, Qena faculty
of medicine and its university hospital,
South valley university, Qena, Egypt.
Mob.: +201224466151
ORCID ID: https://orcid.org/0000-0002-0710-6487
Email: ahmed_adel0391@med.svu.edu.eg

\section{Introduction}

A fragility fracture is defined by the World Health Organization as "a fracture caused by an injury that would be insufficient to fracture a normal bone as a result of reduced compressive and/or torsional strength of bone" ${ }^{\prime \prime}$ Fragility hip fracture is considered a rising worldwide healthcare problem ${ }^{2}$. In 2000, the reported worldwide incidence of hip fractures in people aged $>50$ years was approximately 1.6 million $^{3}$. With aging and expansion of the world population, the annual es- 
timate of fragility hip fractures is expected to reach 2.6 million by 2025 and 4.5 million by $2050^{4}$. In the Middle East, approximately 52,000 hip fractures were recorded in 1990 , which is suspected to increase to 192,000 by 2025 and to 435,000 by $2050^{5}$.

A recent systematic review by Downey C et al. in 2019, included data from 8 national hip fracture registries and studies reporting one-year mortality covering 36 countries, they found that the mean one-year mortality rate was $22 \%$ (ranging from $2.4 \%$ to $34.8 \%)^{6}$. The highest risk of mortality occurs within three months ${ }^{7,8}$; however, the mortality remains high compared to the agematched controls for as long as ten years?.

Apart from increasing mortality, a high percentage of physical and mental morbidities with increasing disability, loss of independence, and increased level of institutionalization may follow ${ }^{10-12}$. This explains the high amount of health and socioeconomic burdens posed by this problem ${ }^{13,14}$.

Most of the literature analysing mortality and morbidity after fragility hip fractures come from developed countries; little information comes from the Middle East and from low and middle income countries (developing countries $)^{15}$. Moreover, there are many controversies about the risk factors predicting mortality associated with fragility hip fractures. To the best of our knowledge there was no detailed mortality rate report after fragility hip fractures from our area (Africa and the Middle East) in the past five years. To help us with proper implementation of a geriatric care program attacking the most significant factors affecting mortality at a proper time, we carried the current study.

\begin{abstract}
Aim
The primary objective of this study was to evaluate the mortality rate (in-hospital, 3-months, 6-months, and one year) after the management of fragility hip fractures in an Egyptian population. The secondary objective was to study the causes of complications, re-admissions, and mortality.
\end{abstract}

\section{Methods}

We conducted a prospective cohort study for all patients diagnosed with a fragility hip fracture admitted to the trauma unit in our institution (level 1 Trauma Centre) from January 2016 to December 2016. Patients less than 65 years old, periprosthetic fractures, and pathological fractures were excluded. Informed consent was obtained from all the patients or their caregivers before enrolling the subjects for this study. The ethical committee of our institution approved the study (IRB no.: 17100171).

\section{Pathway of patients with fragility hip fracture}

As the patient with suspected fragility hip fracture arrives at the emergency department at our hospital (in the current series $75.5 \%$ of patients presented at the same day of trauma, $24.5 \%$ presented within one week after trauma),

Evaluation: The first evaluation and history taking are performed by an orthopaedic resident including details of trauma mechanism, preinjury activity level, and preexisting medical comorbidities. Full physical examination (general and local) is performed. Prescribing appropriate analgesia before transferringthe patient to the radiology department, usually, an AP pelvis and a lateral view of the injured hip are performed. After confirming the diagnosis, non-adhesive skin traction is applied to the injured limb (in case of trochanteric fractures).

Admission: the patient is admitted and transferred to a standard inpatient trauma ward, and anticoagulation in the form of low molecular weight heparin should be initiated unless contraindicated. Preparation of the patient for surgery is initiated within 8 hours after admission after consultation of internist and anesthesiologist (when needed). If the patient is ready for surgery (from a medical and surgical perspective), it is performed within 36 hours after admission (anticoagulation is stopped 8 hours before surgery).

Surgery: Patients were given priority in the operative list, and choice of anesthesia is according to the preference of the anesthesiologist (either neuraxial or general). All surgeries were performed by well-trained orthopaedic surgeons (at least two years of experience dealing with such cases). Surgical decision and device to be used were according to the policy of our department (for trochanteric fractures patients, fixation was performed using a sliding hip screw, and for patients with neck of femur fracture, all received a cemented bipolar hemiarthroplasty).

Post-operative: patients were transferred to the recovery area for at least 8 hours; critical patients were transferred to the ICU. Postoperative plain radiographs were obtained, then patients were transferred to the ward, the usual medications prescribed postoperatively are antibiotics, analgesics, and anticoagulants (started 12 hours postoperative). Full blood picture is performed the first day postoperatively, and blood transfusion was advised if the $\mathrm{Hb}$ level is below $8 \mathrm{~g} / \mathrm{dl}$. Patients having hemiarthroplasty were allowed for an assisted toe-touch weight-bearing protocol at postoperative day one.

African Health Sciences, Vol 21 Issue 2, June, 2021 
Rehabilitation: Weight-bearing was restricted for Patients with trochanteric fractures; however, mobilization in bed at least once each day was done with assistance from members of the health care staff, including nurses. Where safe and appropriate, family members or caregivers were encouraged to assist with daily mobilization.

Discharge: Since there was no specialized orthogeriatric care unit, Patients usually were discharged from the hospital by postoperative day three unless they had either a medical or a surgical complication necessitating their stay at the hospital. Patients were either discharged to their home or the nearest health facility if needed. Patients were transferred to the nearest hospital (if needed).

Follow up: Follow up visits were scheduled at two weeks for suture removal, six weeks for radiographs recheck, three months, six months, 12 months, and then annually. Patients were advised to visit the hospital if any major incident happened between these intervals, or at least make a telephone call for any inquiries. In case of death, the relative or the caregiver was asked about the time and place of death and whether the patient was admitted to any hospital before death or not.

\section{Data collection}

Two independent researchers collected the data via a structured questionnaire designed specifically for this study that contains demographic data (age, sex, residence, smoking, co-morbidities, American Society of Anaesthesiologists (ASA) score, type of the fracture, the timing of the trauma before hospital admission and causes of delay if any), intraoperative data (type of operation, timing after admission and causes of delay if any, and intraoperative complications or mortality), postoperative in-hospital data (length of stay, compli- cations, mortality), and post-discharge data which were collected at 3, 6, and 12 months (complications, mortality, re-admission). The STROBE guidelines were used to ensure the quality of reporting of this observational study ${ }^{16}$.

\section{Statistical analysis}

Data were analysed using SPSS version 21* (IBM-SPSS Inc, Chicago, IL, USA). Frequency tables were examined to explore missing data, errors in the data, and data inconsistency. Missing data were treated by replacing the missing value with median values. Descriptive statistics such as means, standard deviations, medians, and percentages were calculated. The Chi-square test or Fisher's Exact test was used to compare the difference in the distribution of frequencies among different groups. For continuous variables, independent t-test analysis and one-way ANOVA were carried out to compare the means of normally distributed data, while the Mann-Whitney U test and Kruskal-Wallis test were calculated to test the median differences of the data that do not follow a normal distribution. The relationships between patient characteristics and survival were analysed by the Kaplan-Meier and Cox Regression Analyses (Forward LR). Age and sex were added as priori variables, and the clinical and demographic factors with proven statistical significance from the univariate analyses were further included in the multivariate Cox Hazard Regression models. A P-value of $\leq 0.05$ was regarded as significant.

\section{Results}

During the study period, 362 patients with fragility hip fractures were admitted to the Trauma Unit of our Hospital. Three pathological fractures and four periprosthetic fractures were excluded. We lost 14.9\% (54 patients) to follow-up after discharge. This left $301 \mathrm{pa}-$ tients eligible for this study. The basic characteristics of the patients are demonstrated in (Table 1). 


\begin{tabular}{|c|c|c|}
\hline Variable & Category & $\mathrm{n}=301(100 \%)$ \\
\hline $\begin{array}{l}\text { Age in years } \\
(\text { Mean } \pm \mathrm{SD})\end{array}$ & \multicolumn{2}{|l|}{$74.2 \pm 0.47$} \\
\hline \multirow{2}{*}{ ASA Class. } & $\operatorname{ASA}(1 \& 2)$ & $\mathrm{n}=254(84.4 \%)$ \\
\hline & $\operatorname{ASA}(3 \& 4)$ & $\mathrm{n}=47(15.6 \%)$ \\
\hline \multirow{2}{*}{ Sex } & Male & $\mathrm{n}=151(51.2 \%)$ \\
\hline & Female & $\mathrm{n}=150(49.8 \%)$ \\
\hline \multirow{2}{*}{ Residence $^{1}$} & Rural & $\mathrm{n}=166(55.1 \%)$ \\
\hline & Urban & $\mathrm{n}=135(44.9 \%)$ \\
\hline \multirow{2}{*}{$\begin{array}{l}\text { Co-morbidity } \\
\text { (DM, HTN, Cardiac, hepatic disease) }\end{array}$} & Yes & $\mathrm{n}=111(36.9 \%)$ \\
\hline & No & $\mathrm{n}=190(63.1 \%)$ \\
\hline \multirow[b]{2}{*}{ Cause of Trauma } & Fall on ground & $\mathrm{n}=278(92.4 \%)$ \\
\hline & $\begin{array}{l}\text { Others (Road Traffic } \\
\text { Accidents, Fall from Height) }\end{array}$ & $\mathrm{n}=23(7.6 \%)$ \\
\hline \multirow{3}{*}{ Diagnosis } & Trochanteric fracture & $\mathrm{n}=172(57.1 \%)$ \\
\hline & NOF fracture & $\mathrm{n}=112(37.2 \%)$ \\
\hline & $\begin{array}{l}\text { Others (Subtrochanteric, } \\
\text { and acetabular fractures) }\end{array}$ & $\mathrm{n}=17(5.7 \%)$ \\
\hline \multicolumn{3}{|c|}{$\begin{array}{l}\text { ASA; American Society of Anesthesiology, DM; Diabetes mellitus, HTN; hypertension, NOF; neck } \\
\text { of the femur } \\
{ }^{1} \text { Rural refers to patients who reside in villages at the periphery of the city where our trauma center } \\
\text { is located (about } 40 \mathrm{~km} \text { far). In contrast, Urban refers to patients living within the city. }\end{array}$} \\
\hline
\end{tabular}

Regarding the mortality rate, in-hospital mortality (one patient died intraoperatively and 24 postoperative) was $8.3 \%$ (25 patients), 3-month mortality was 39.2\% (118 patients), 6-months mortality was $44.1 \%$ (133 patients), and at 12 months follow-up a total of 159 patients died constituting a one-year mortality rate of $52.8 \%$, of those deaths, $48.4 \%$ (77 patients) were males, and $51.6 \%$ (82 patients) were females, the overall survival after 1 -year was $47.2 \%$ (142 patie/span>nts) (Figure 1). 


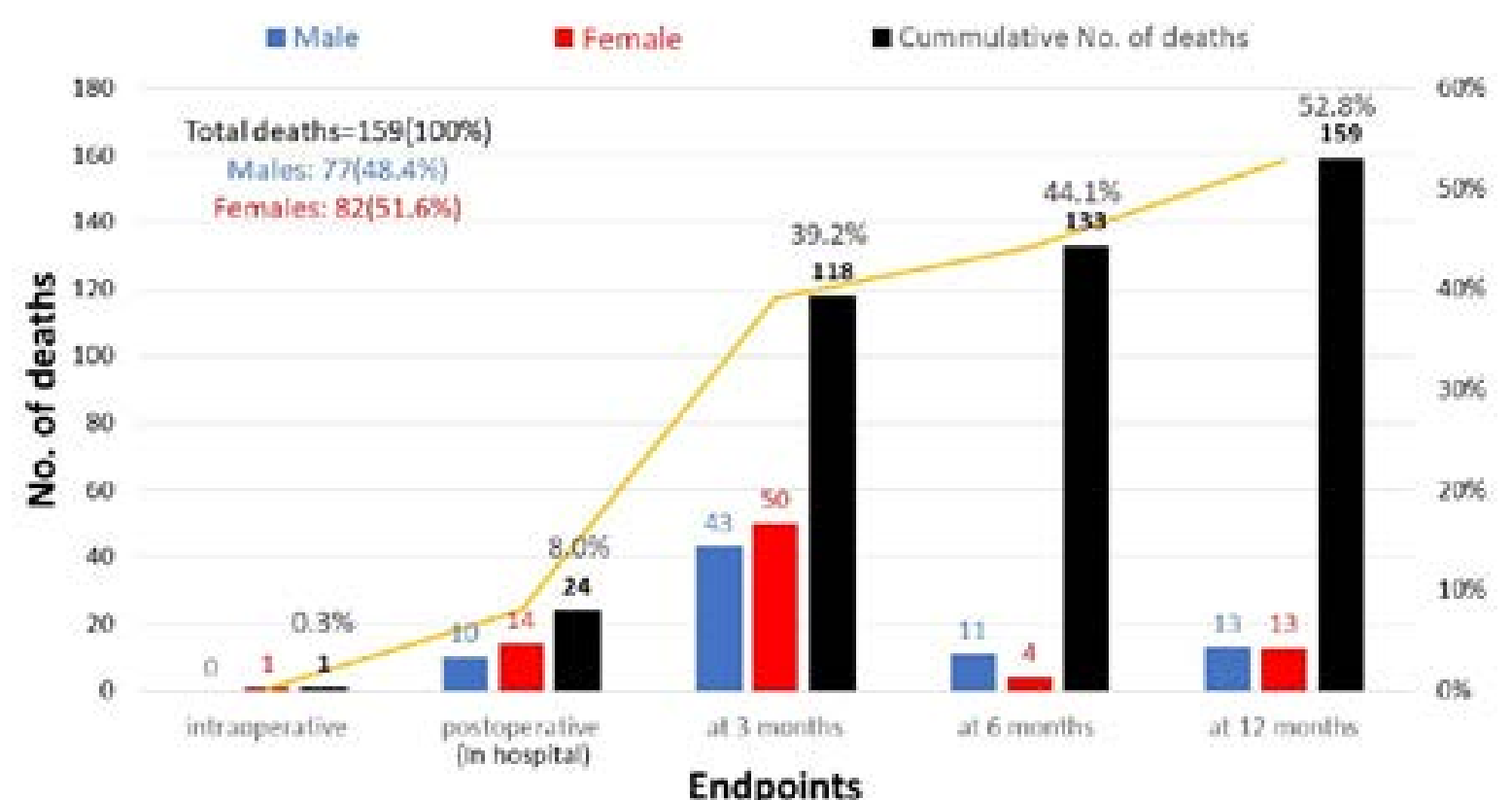

Figure 1: Mortality rate at each study endpoints (stratified by sex).

Complications occurred in 19.3\% (58 patients), which was distributed as follows: intra-operative blood loss that necessitated blood transfusion occurred in 3\% ( 9 patients), chest infection (pneumonia) in 1\% (3 patients), and revision of fixation in $0.3 \%$ (1 patient). Deterioration of the general condition with ICU admission occurred in 1\% (3 patients). After discharge, surgical site infection occurred in $11.3 \%$ (34 patients), and metal failure in 3\% ( 9 patients).

Re-admission was required in $7.3 \%$ (22 patients). The most common reason for re-admissions was infection in $36.3 \%$ (8 patients), metal failure in $27.3 \%$ (6 patients), non-surgical causes in $27.3 \%$ (6 patients), and unrelated operations in $9.1 \%$ ( 2 patients). Attrition rates were found as follows: In-hospital attrition rate $8.6 \%$, at 3 months $40 \%$, at 6 months $8.5 \%$ and after completing 1 year it was $16.8 \%$.

Factors associated with 1-year mortality and significance of each was calculated by running a univariate analysis as shown in (Table 2). 


\begin{tabular}{|c|c|c|c|c|}
\hline & & $\begin{array}{l}\text { Alive } \\
\left(\mathrm{No}_{0}=142\right)\end{array}$ & $\begin{array}{l}\text { Dead } \\
\left(\mathrm{No}_{0}=159\right)\end{array}$ & P-value \\
\hline \multicolumn{2}{|c|}{ Age in years (Mean \pm SD) } & $71.9 \pm 6.9$ & $76.2 \pm 8.6$ & $<0.001 *$ \\
\hline \multirow{2}{*}{ Sex } & Male & $73(48.7 \%)$ & $77(51.3 \%)$ & \multirow{2}{*}{$=0.344^{\dagger}$} \\
\hline & Female & $69(45.7 \%)$ & $82(54.3 \%)$ & \\
\hline \multirow{2}{*}{ Residence } & Rural & $82(49.4 \%)$ & $84(50.6 \%)$ & \multirow{2}{*}{$=0.392$} \\
\hline & Urban & $60(44.5 \%)$ & $75(55.6 \%)$ & \\
\hline \multirow{4}{*}{ Co-morbidity } & $\mathrm{DM}$ & $20(37 \%)$ & $34(63 \%)$ & $=0.055^{\dagger}$ \\
\hline & HTN & $12(38.7 \%)$ & $19(61.3 \%)$ & $=0.192^{\dagger}$ \\
\hline & Cardiac & $5(29.4 \%)$ & $12(70.6 \%)$ & $=0.041^{\dagger}$ \\
\hline & Hepatic & $0(0 \%)$ & $19(100 \%)$ & $<0.001^{\dagger}$ \\
\hline \multirow{2}{*}{ Diagnosis $(n=287)$} & NOF fracture & $67(59.3 \%)$ & $46(40.7 \%)$ & \multirow{2}{*}{$=0.002$} \\
\hline & Trochanteric fracture & $71(40.8 \%)$ & $103(59.2 \%)$ & \\
\hline \multirow{2}{*}{ ASA Classification } & ASA $(1 \& 2)$ & $129(50.8 \%)$ & $125(49.2 \%)$ & \multirow{2}{*}{$=0.004$} \\
\hline & ASA $(3 \& 4)$ & $13(27.7 \%)$ & $34(72.3 \%)$ & \\
\hline \multirow{2}{*}{$\begin{array}{l}\text { Complications after } \\
\text { operation }\end{array}$} & \begin{tabular}{|l} 
No \\
\end{tabular} & $134(57.8 \%)$ & $98(42.2 \%)$ & \multirow{2}{*}{$<0.001^{\dagger}$} \\
\hline & Yes & $8(11.6 \%)$ & $61(88.4 \%)$ & \\
\hline \multirow{2}{*}{ Re-admission } & No & $134(57.8 \%)$ & $98(42.2 \%)$ & \multirow{2}{*}{$<0.001^{\dagger}$} \\
\hline & Yes & $8(11.6 \%)$ & $61(88.4 \%)$ & \\
\hline \multirow{3}{*}{$\begin{array}{l}\text { Timing of } \\
\text { Operation }\end{array}$} & $<48$ hours & $68(51.9 \%)$ & $63(48.1 \%)$ & \multirow{3}{*}{$=0.282^{\dagger}$} \\
\hline & $48-96$ hours & $37(46.3 \%)$ & $43(53.7 \%)$ & \\
\hline & $>96$ hours & $37(41.1 \%)$ & $53(58.9 \%)$ & \\
\hline \multicolumn{2}{|c|}{ Hospital Stay in days (Mean \pm SD) } & $5.65 \pm 2.5$ & $6.86 \pm 3.6$ & $=0.003^{\ddagger}$ \\
\hline \multicolumn{5}{|c|}{$\begin{array}{l}\text { DM; Diabetes mellitus, HTN; hypertension, NOF; neck of femur, ASA; Amer } \\
\text { Anesthesiology. } \\
\text { *Independent t-test was used to compare the mean difference between the two grou } \\
\text { 'Chi-square analysis was used to compare the difference in proportions } \\
\text { Mann Whitney U test to compare the median difference between the two groups } \\
\text {--Significance level is considered when } p \leq 0.05\end{array}$} \\
\hline
\end{tabular}

Identifying factors as a risk for 1-year mortality after hip fractures were done using the multivariate Cox Hazard regression analysis as shown in (Table 3). The follow- ing factors were identified as the risk factors for 1-year mortality after hip fractures: age, ASA 3-4, trochanteric fractures, associated cardiac disease, associated hepatic disease, total hospital stay, and postoperative morbidity (infection, and metal failure). 


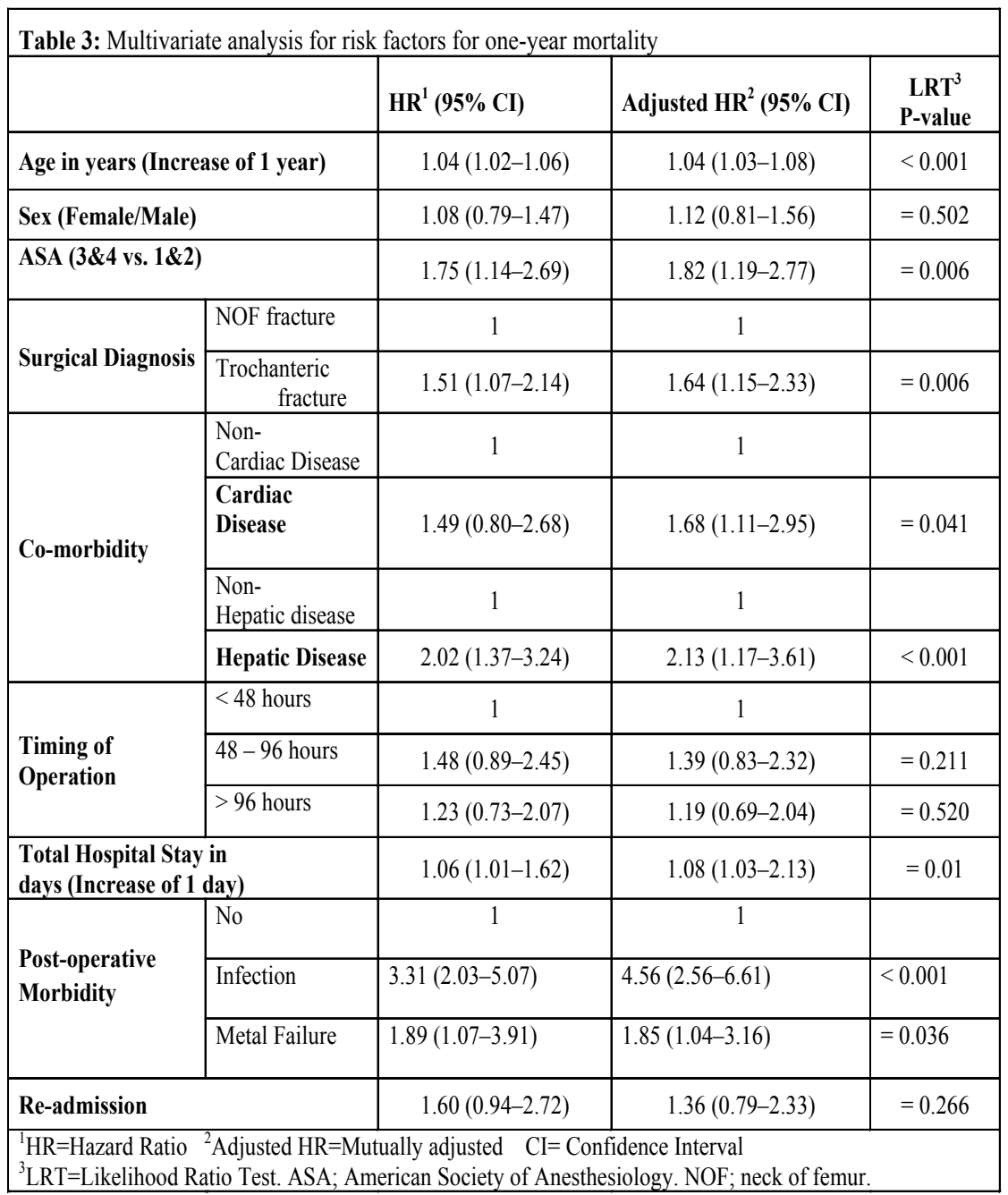

\section{Discussion}

Fragility hip fractures considered as a significant public health concern mostly associated with increased morbidity as well as mortality compared to other osteoporos related fractures ${ }^{17,18}$, prolonged recumbency related complications mainly deep vein thrombosis, pulmonary embolism, and pneumonia, which may occur during hospitalization or even after patients discharge had been considered as the leading causes for increased mortality rates ${ }^{18-20}$.

In our cohort, we found an in hospital mortality $(8.3 \%)$ similar to previous studies, 159 died by the end of 1 -year constituting a total mortality rate of $52.8 \%$ of the whole study population; most of these mortalities were reported at 3-months follow up which represented $58.5 \%$ of the total mortalities reported in our study. We found that age, advanced ASA grade ( 3 or 4 ), associated cardiac or hepatic disease, trochanteric fractures, post-operative infection or metal failure, and length of hospital stay were significantly associated with mortality.

Hue et al. conducted a meta-analysis that included 75 studies involving 64,316 patients and reported that the overall inpatient or 1-month mortality was $13.3 \%$, 3-6onths was $15.8 \%$, one-year $24.5 \%$, and after 2-year it reached up to $34.5 \%{ }^{21}$.

We reported $8.3 \%$ of in-hospital mortality which resembles what had been reported from developed countries, for example, the stated rates were between 1.6\% and $1.8 \%$ in $\mathrm{USA}^{22,23}, 5.4 \%$ in Italy ${ }^{24}, 6.3 \%$ in Canada ${ }^{25}$, $15 \%$ in $\mathrm{UK}^{26}$, and $1.3 \%$ in Turkey ${ }^{27}$.

In our study, $58.5 \%$ of the total deaths occurred in the first 3-months, which resembles what was reported by some authors. Holvik et al. reported $58 \%$ of the total mortalities to happen in the first 3-months in their study of 567 patients with fragility hip fractures ${ }^{28}$. Lopez et al. reported a higher frequency of mortality $65.3 \%$ during the first 3 months after fragility hip fractures, which then plateaued 8 .

Our 1 -year mortality rate was $52.8 \%$, which was as high as what was historically reported from the USA by Beals RK. who showed a 50\% mortality rate for patients with hip fractures admitted between 1956 and $1961^{29}$, however, recently the mortality rates have decreased as low as $21 \%$ in $\mathrm{USA}^{30}, 8.1 \%$ in Italy $31,11.5 \%$ in $\operatorname{Japan}^{32}$, $23 \%$ in Netherlands ${ }^{33}, 23.5 \%$ in Norway ${ }^{28}, 24.8 \%$ in Sweden ${ }^{34}, 33.5 \%$ in the $\mathrm{UK}^{35}$, and $22.5 \%$ in $\mathrm{Spain}^{8}$, this decrement may be attributed to the advancements in 
fracture stabilization techniques, orthogeriatric care, and increased awareness about healthcare problem associated with fragility hip fractures.

Mortality reports at 1 -year from developing countries also showed variable rates, in Thailand, it was reported to be $18 \%{ }^{36}, 30 \%$ and $35 \%$ in Brazil ${ }^{37,38}$, Tunisia, Saudi Arabia and Sudan (representing an African and Middle East countries) the rates were $28.4 \%{ }^{15}, 26.98 \%{ }^{39}$ and $16.7 \%{ }^{40}$ respectively.

In concordance with most authors ${ }^{8,15,27,33-38,41-43}$, we also observed that increasing age is a risk factor for mortality. However, Holvih et al. could not find a correlation between age and 1-year mortality in a study consisting of 567 patients with hip fracture and aged above 65 years $^{28}$. A similar finding was also reported by Mossey et al. in a group of 219 patients with hip fractures ${ }^{44}$. Different cut-off values were reported for increasing mortality: $>70$ years $43,>80$ years 8 , and $>85$ years $^{45}$.

We did not detect gender as a risk factor for mortality after hip fracture, which was in agreement with many other studies $^{27,28,41,42}$. However, the effect of gender on mortality after hip fracture is debatable. Male gender has been reported by many authors to be a risk factor for increased mortality after hip fracture $8,15,33-38,43,46,47$.

Lopez et al. found that the risk of death was 2.44-folds higher in males8. Endo et al. observed more complications and higher mortality in males during the postoperative hospital stay; at 1-year post-operation, the risk of death for males were double than that of females ${ }^{46}$. A similar finding was also reported by Carpintero et al. who suggested that men have a poor nutritional status and more co-morbidities compared to women; this, in turn, increases the likelihood of death after sustaining a hip fracture ${ }^{48}$. Wehren et al. suggested that infections, such as pneumonia and septicaemia, are more common in male patients, a finding that could explain the higher mortality in male patients ${ }^{49}$. On the contrary, Otzuruk et al. found that the female gender is a risk factor for mortality due to the frailty of females in their population $^{50}$.

As reported in most of the literature, associated co-morbidities increase the risk of death ${ }^{41,43,51}$. The patients with ASA 3 and 4 are at the highest risk ${ }^{27,28,39}$. Regarding the type of co-morbidity, we found that the riskiest co-morbidities were hepatic, followed by cardiovascular co-morbidities.

Ercin et al. identified central nervous system co-morbidities as a specific condition that affects mortality ${ }^{27}$, whereas Sepah et al. stated that cyclic vomiting syndrome co-morbidities are the most dangerous15. Some studies ${ }^{15,27}$ reported increased mortality with $>2$ different co-morbidities in the same patient. Roche et al. ${ }^{35}$ stated that $>3$ co-morbidities are the most significant preoperative risk factor, especially respiratory diseases, and malignancy.

Unlike many authors who could not find a correlation between the fracture type and mortality rates $8,15,27,38,42$, in our study, mortality was significantly higher in cases with extracapsular fractures. Similarly, Keene et al. observed higher mortality and morbidity in the extracapsular fracture group ${ }^{26}$.

Early surgery, within 24 hours, maybe challenging to achieve, especially in a medically unfit patient who needs more time for general condition optimization ${ }^{27}$, 50,52 . However, it is generally agreed that hip fractures should be stabilized as early as possible, as recommended by the Royal College of Physicians ${ }^{52}$. Weil et al. reported that in Israel by 2019, more than $85 \%$ of hip fracture patients received early surgery (within 48 hours after admission), this led to a reduction of the national 1-year mortality of less than $19 \%{ }^{53}$.

In our study, we did not observe a significant association between early surgery and reduced mortality. This is in contrast to the findings of Colais et al., who reported lower 1-year mortality in patients with hip fractures operated within two days of admission ${ }^{54}$. Bottle et al. ${ }^{55}$, as well as Elliott et al. ${ }^{56}$, reported the same findings. On the other hand, other studies failed to find a correlation between early surgery and mortality $28,34,42,50,57$

The most common causes for readmission in our study were infection $(36.3 \%)$, followed by medical causes $(27.3 \%)$. Hyes et al. found that the most common reason for re-admission after fragility hip fractures was medical complications, especially bronchopneumonia ${ }^{58}$. The strengths of this study include a large number of patients treated in the same center by a dedicated team which is expected to employ a uniform standard of care and, hence, provide more reliable results. However, this study had several limitations: firstly, as our hospital is a level-1 trauma center with a huge catchment area of more than 20 million inhabitants; therefore, after patients being discharged from our center, different postoperative rehabilitation protocols were applied in various centers, which mostly lacked the concept of orthogeriatric specialized care, which may have its effect on increased mortality rates which we considered as a major limitation of this study. Secondly, as the substan- 
tially high number of patients $(14.9 \%)$ lost to follow up and received their postoperative care and rehabilitation in other hospitals, they were included only in in-hospital mortality and were excluded from the remaining univariate and multivariate analyses. Thirdly, patients included in the study are treated in a trauma service that offers care free of charge, these patients mostly had a low socioeconomic status, and lacked proper care at home after hospital discharge; and possibly if the hip fracture patients with a higher socioeconomic state were included with better home care, this would have changed the mortality rates. Lastly, we compared the results from the current study with what had been reported in the western populations which may have different demographic characteristics that affect the outcome, even the ethnicity of the study group can affect the study outcomes as reported in a study by Lakstein et al. ${ }^{59}$, the main reason behind this is the paucity of detailed published reports during the last 5 years on mortality or morbidity rates after fragility hip fracture from our part of the world (Africa or the Middle East).alized due to financial and logistic reasons however, we are in the process of implementing this program to be part of the standard of care.

Further multicenter studies including national as well as nearby countries trauma institutions should be initiated to define the morbidity and mortality incidence among fragility hip fracture patients in our locality and its possible determinants.

Establishment of an African hip registry to deal with all issues related to fragility hip fractures and its economic burden is mandatory.

\section{Conclusion}

Our in-hospital mortality rate was close to what had been reported from developed countries, reflecting good standards of initial geriatric care provided in the study setting. However, 3- and 12-months mortalities were unexpectedly high, reflecting the deficiency in the socioeconomic aspect of fragility hip fractures care. We believe that lack of rehabilitation centres, deficiency of proper geriatric postoperative care programs and economic reasons are the main factors for the high mortality rate.

\section{Compliance with Ethical Standards}

Study setting: Assiut University Hospital, Assiut, Egypt.

\section{Conflict of interest}

The authors declare that they have no conflict of interest.

\section{Funding}

There is no funding source.

\section{Ethical approval}

This article does not contain any experimental studies with human participants or animals performed by any of the authors, and the ethical committee of our institution approved it: Faculty of Medicine, Assiut University, Egypt (IRB no.: 17100171) (Telephone, Fax: +20882332278, ethics-committee12@ yahoo.com, http://afm.edu.eg) Clinical Trials.gov ID: NCT03150355

\section{References}

1. Organization WH. Guidelines for preclinical evaluation and clinical trials in osteoporosis: World Health Organization; 1998.

2. Saez-Lopez P, Branas F, Sanchez-Hernandez N, Alonso-Garcia N, Gonzalez-Montalvo JI. Hip fracture registries: utility, description, and comparison. Osteoporos Int. 2017;28(4):1157-66.

3. Johnell O, Kanis JA. An estimate of the worldwide prevalence and disability associated with osteoporotic fractures. Osteoporos Int. 2006;17(12):1726-33.

4. Gullberg B, Johnell O, Kanis JA. World-wide projections for hip fracture. Osteoporos Int. 1997;7(5):407-13.

5. Cooper C, Campion G, Melton LJ, 3rd. Hip fractures in the elderly: a world-wide projection. Osteoporos Int. 1992;2(6):285-9.

6. Downey C, Kelly M, Quinlan JF. Changing trends in the mortality rate at 1-year post hip fracture - a systematic review. World Journal of Orthopedics. 2019;10(3):16675.

7. Farahmand BY, Michaelsson K, Ahlbom A, Ljunghall S, Baron JA, Swedish Hip Fracture Study G. Survival after hip fracture. Osteoporos Int. 2005;16(12):1583-90.

8. Alegre-Lopez J, Cordero-Guevara J, Alonso-Valdivielso JL, Fernandez-Melon J. Factors associated with mortality and functional disability after hip fracture: an inception cohort study. Osteoporos Int. 2005;16(7):72936.

9. Haentjens P, Magaziner J, Colon-Emeric CS, Vanderschueren D, Milisen K, Velkeniers B, et al. Meta-analysis: excess mortality after hip fracture among older women and men. Ann Intern Med. 2010;152(6):380-90. 10. Cree M, Carriere KC, Soskolne CL, Suarez-Almazor 
M. Functional dependence after hip fracture. Am J Phys Med Rehabil. 2001;80(10):736-43.

11. Lenze EJ, Munin MC, Skidmore ER, Dew MA, Rogers JC, Whyte EM, et al. Onset of depression in elderly persons after hip fracture: implications for prevention and early intervention of late-life depression. $J$ Am Geriatr Soc. 2007;55(1):81-6.

12. Butler A, Hahessy S, Condon F. The effect of time to surgery on functional ability at six weeks in a hip fracture population in Mid-West Ireland. Int J Orthop Trauma Nurs. 2017;26:36-42 PubMed.

13. Johnell $\mathrm{O}$. The socioeconomic burden of fractures: today and in the 21st century. Am J Med. 1997;103(2A):20S-5S; discussion 5S-6S.

14. Youm T, Koval KJ, Zuckerman JD. The economic impact of geriatric hip fractures. Am J Orthop (Belle Mead NJ). 1999;28(7):423-8.

15. Jamal Sepah Y, Umer M, Khan A, Ullah Khan Niazi A. Functional outcome, mortality and in-hospital complications of operative treatment in elderly patients with hip fractures in the developing world. Int Orthop. 2010;34(3):431-5. PubMed

16. von Elm E, Altman DG, Egger M, Pocock SJ, Gotzsche PC, Vandenbroucke JP, et al. The Strengthening the Reporting of Observational Studies in Epidemiology (STROBE) statement: guidelines for reporting observational studies. J Clin Epidemiol. 2008;61(4):344-9. PubMed

17. Peeters CM, Visser E, Van de Ree CL, Gosens T, Den Oudsten BL, De Vries J. Quality of life after hip fracture in the elderly: A systematic literature review. Injury. 2016;47(7):1369-82. PubMed

18. Siris ES. Patients with hip fracture: what can be improved? Bone. 2006;38(2):8-12. PubMed

19. Friedman SM, Mendelson DA, Bingham KW, Kates SL. Impact of a comanaged Geriatric Fracture Center on short-term hip fracture outcomes. Arch Intern Med. 2009;169(18):1712-7. PubMed

20. Dharmarajan TS, Banik P. Hip fracture. Risk factors, preoperative assessment, and postoperative management. Postgrad Med. 2006;119(1):31-8.

21. Hu F, Jiang C, Shen J, Tang P, Wang Y. Preoperative predictors for mortality following hip fracture surgery: a systematic review and meta-analysis. Injury. 2012;43(6):676-85.

22. Cornwall R, Gilbert MS, Koval KJ, Strauss E, AL. S. Functional outcomes and mortality vary among different types of hip fractures: a function of patient characteristics. Clin Orthop Relat Res. 2004;(425):64-71.

23. Hannan EL, Magaziner J, Wang JJ, Eastwood EA, Silberzweig SB, Gilbert M, et al. Mortality and locomotion 6 months after hospitalization for hip fracture: risk factors and risk-adjusted hospital outcomes. JAMA. 2001;285(21):2736-42.

24. Franzo A, Francescutti C, Simon G. Risk factors correlated with post-operative mortality for hip fracture surgery in the elderly: a population-based approach. Eur J Epidemiol. 2005;20(12):985-91.

25. Jiang HX, Majumdar SR, Dick DA, Moreau M, Raso J, Otto DD, et al. Development and initial validation of a risk score for predicting in-hospital and 1-year mortality in patients with hip fractures. J Bone Miner Res. 2005;20(3):494-500.

26. Keene GS, Parker MJ, Pryor GA. Mortality and morbidity after hip fractures. BMJ. 1993;307(6914):1248-50. 27. Ercin E, Bilgili MG, Sari C, Basaran SH, Tanriverdi B, Edipoglu E, et al. Risk factors for mortality in geriatric hip fractures: a compressional study of different surgical procedures in 785 consecutive patients. Eur J Orthop Surg Traumatol. 2017;27(1):101-6.

28. Holvik K, Ranhoff AH, Martinsen MI, Solheim LF. Predictors of mortality in older hip fracture inpatients admitted to an orthogeriatric unit in oslo, norway. $J \mathrm{Ag}$ ing Health. 2010;22(8):1114-31.

29. Beals RK. Survival following hip fracture. Long follow-up of 607 patients. J Chronic Dis. 1972;25(4):235-44. 30. Okike K, Chan PH, Paxton EW. Effect of Surgeon and Hospital Volume on Morbidity and Mortality After Hip Fracture. The Journal of Bone and Joint Surgery American volume. 2017;99(18):1547-53.

31. Bellelli G, Frisoni GB, Turco R, Trabucchi M. Depressive symptoms combined with dementia affect 12-months survival in elderly patients after rehabilitation post-hip fracture surgery. Int J Geriatr Psychiatry. 2008;23(10):1073-7.

32. Muraki S, Yamamoto S, Ishibashi H, Nakamura K. Factors associated with mortality following hip fracture in Japan. J Bone Miner Metab. 2006;24(2):100-4.

33. Folbert EC, Hegeman JH, Vermeer M, Regtuijt EM, van der Velde D, Ten Duis HJ, et al. Improved 1-year mortality in elderly patients with a hip fracture following integrated orthogeriatric treatment. Osteoporos Int. 2017;28(1):269-77.

34. Ami Hommel, Kerstin Ulander, Karin B. Bjorkelund , Per-Ola Norrman, Hans Wingstrand, Thorngren. K-Go. Influence of optimised treatment of people with hip fracture on time to operation, length of hospital stay, reoperations and mortality within 1 year. Injury, Int J Care Injured. 2008;39:1164-74.

35. Roche JJ, Wenn RT, Sahota O, Moran CG. Effect of comorbidities and postoperative complications on mortality after hip fracture in elderly people: prospective observational cohort study. BMJ. 2005;331(7529):1374. 36. Vaseenon T, Luevitoonvechkij S, Wongtriratanachai 
P, Rojanasthien S. Long-term mortality after osteoporotic hip fracture in Chiang Mai, Thailand. J Clin Densitom. 2010;13(1):63-7.

37. Pereira SR, Puts MT, Portela MC, Sayeg MA. The impact of prefracture and hip fracture characteristics on mortality in older persons in Brazil. Clin Orthop Relat Res. 2010;468(7):1869-83.

38. Garcia R, Leme MD, Garcez-Leme LE. Evolution of Brazilian elderly with hip fracture secondary to a fall. Clinics (Sao Paulo). 2006;61(6):539-44.

39. Sadat-Ali M, Alfaraidy M, AlHawas A, Al-Othman AA, Al-Dakheel DA, Tayara BK. Morbidity and mortality after fragility hip fracture in a Saudi Arabian population: Report from a single center. The Journal of International Medical Research. 2017;45(3):1175-80.

40. Elhadi AS, Abdelgadir AH, Elbushra EM, Gashi YN. Outcome of primary cemented bipolar hemiarthroplasty in older patients with unstable hip fracture: A prospective study. Journal of Musculoskeletal Surgery and Research. 2019;3(2):196.

41. Mnif H, Koubaa M, Zrig M, Trabelsi R, Abid A. Elderly patient's mortality and morbidity following trochanteric fracture. A prospective study of 100 cases. Orthop Traumatol Surg Res. 2009;95(7):505-10.

42. Hershkovitz A, Polatov I, Beloosesky Y, Brill S. Factors affecting mortality of frail hip-fractured elderly patients. Arch Gerontol Geriatr. 2010;51(2):113-6.

43. Katsoulis M, Benetou V, Karapetyan T, Feskanich

D, Grodstein F, Pettersson-Kymmer U, et al. Excess mortality after hip fracture in elderly persons from Europe and the USA: the CHANCES project. J Intern Med. 2017;281(3):300-10.

44. Mossey JM, Mutran E, Knott K, Craik R. Determinants of recovery 12 months after hip fracture: the importance of psychosocial factors. Am J Public Health. 1989;79(3):279-86.

45. Aharonoff GB, Koval KJ, Skovron ML, Zuckerman JD. Hip fractures in the elderly: predictors of one year mortality. J Orthop Trauma. 1997;11(3):162-5.

46. Endo Y, Aharonoff GB, Zuckerman JD, Egol KA, Koval KJ. Gender differences in patients with hip fracture: a greater risk of morbidity and mortality in men. $J$ Orthop Trauma. 2005;19(1):29-35.

47. Skuladottir SS, Gudmundsdottir E, Mogensen B, Masdottir HR, Gudmundsdottir H, Jonsdottir LA, et al. Hip fractures among older people in Iceland between 2008 and 2012. Int J Orthop Trauma Nurs. 2019;32:27-31. 48. Carpintero P, Lopez P, Leon F, Lluch M, Montero M, C. A. Men with hip fractures have poorer nutritional status and survival than women: a prospective study of 165 patients. Acta Orthop. 2005;76(3):331-5.

49. Wehren LE, Hawkes WG, Orwig DL, Hebel JR, Zimmerman SI, J. M. Gender differences in mortality after hip fracture: The role of infection. Journal of Bone and Mineral Research. 2003;18:2231-7.

50. Ozturk A, Ozkan Y, Akgoz S, Yalcyn N, Ozdemir RM, Aykut S. The risk factors for mortality in elderly patients with hip fractures: postoperative one-year results. Singapore Med J. 2010;51(2):137-43.

51. Vidal EI, Coeli CM, Pinheiro RS, Jr. CK. Mortality within 1 year after hip fracture surgical repair in the elderly according to postoperative period: a probabilistic record linkage study in Brazil. Osteoporosis Int. 2006;17:1569-76. PubMed

52. Shiga T, Wajima Z, Ohe Y. Is operative delay associated with increased mortality of hip fracture patients? Systematic review, meta-analysis, and meta-regression. Can J Anaesth. 2008;55(3):146-54. PubMed

53. Weil YA, Bernstein BP, Maqungo S, Khoury A, Liebergall M, Laubscher M. Hip fracture care and national systems in Israel and South Africa. OTA International. 2020;3(1):e065.

54. Colais P, Di Martino M, Fusco D, Perucci CA, Davoli $\mathrm{M}$. The effect of early surgery after hip fracture on 1-year mortality. BMC Geriatr. 2015;15:141.

55. Bottle A, Aylin P. Mortality associated with delay in operation after hip fracture: observational study. BMJ. 2006;332(7547):947-51.

56. Elliott J, Beringer T, Kee F, Marsh D, Willis C, Stevenson $\mathrm{M}$. Predicting survival after treatment for fracture of the proximal femur and the effect of delays to surgery. J Clin Epidemiol. 2003;56(8):788-95.

57. Siegmeth AW, Gurusamy K, Parker MJ. Delay to surgery prolongs hospital stay in patients with fractures of the proximal femur. J Bone Joint Surg Br. 2005;87(8):11236.

58. Heyes GJ, Tucker A, Marley D, Foster A. Predictors for Readmission up to 1 Year Following Hip Fracture. Arch Trauma Res. 2015;4(2):e27123.

59. Lakstein D, Cohen O, Daglan E, Haimovich Y, Tan Z. Mortality and Function after Hip Fractures in Different Ethnic Populations in Israel. The Israel Medical Association Journal: IMAJ. 2018;20(9):553-6.

60. Mahran DG, Farouk O, Ismail MA, Alaa MM, Eisa A, Ragab, II. Effectiveness of home based intervention program in reducing mortality of hip fracture patients: A non-randomized controlled trial. Arch Gerontol Geriatr. 2019;81:8-17 PubMed. 